\title{
Stage II Skin Cancer
}

National Cancer Institute

\section{Source}

National Cancer Institute. Stage II Skin Cancer. NCI Thesaurus. Code C5582.

Stage II includes: T2, N0, M0. T2: Tumor size greater than $2 \mathrm{~cm}$ in greatest dimension or tumor of any size with two or more high-risk features. High-risk features for the primary tumor staging are defined as follows: depth/invasion of more than $2 \mathrm{~mm}$ thickness; Clark level equal or greater than IV; and perineural invasion. Anatomic location: primary site ear and primary site non-hair-bearing lip. Differentiation: poorly differentiated or undifferentiated. NO: No regional lymph node metastasis. M0: No clinical or radiographic evidence of distant metastasis. (AJCC 7th ed.) 